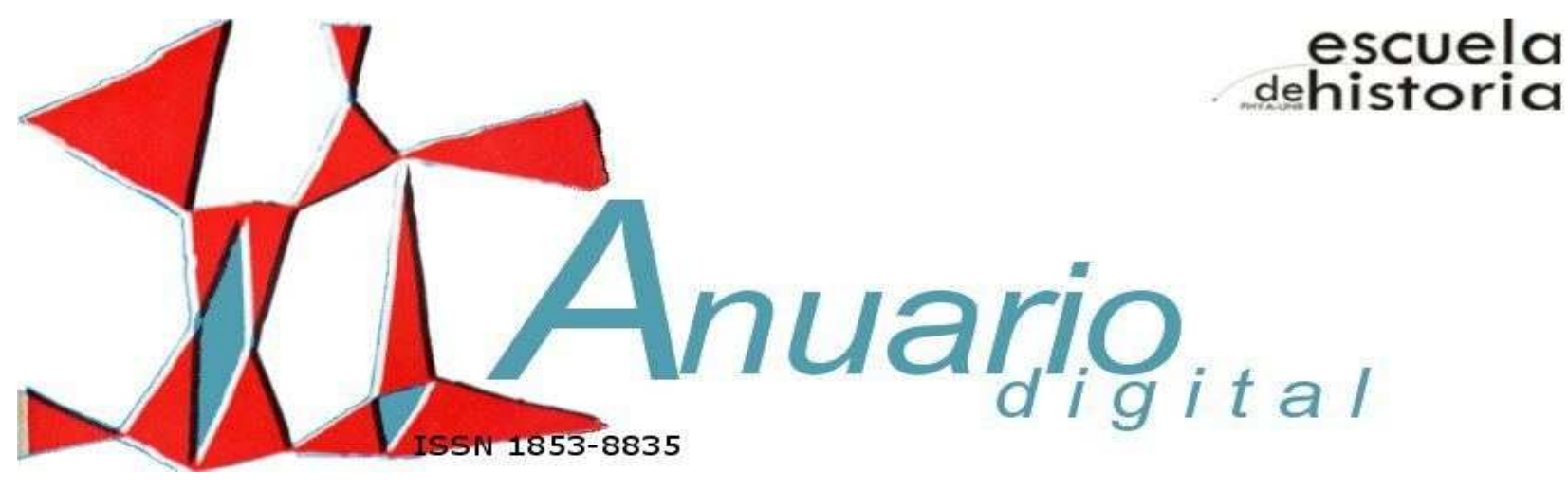

Revolución, Sustantivo Femenino

Revolution, female noun

ANDREA D'ATRI

Instituto del Pensamiento Socialista "Karl Marx"; Buenos Aires; Argentina andreadatri@gmail.com

RESUMEN

"A nadie se le pasó por las mentes que el Día de la Mujer pudiera convertirse en el primer día de la revolución.", dice León Trotsky en su Historia de la Revolución Rusa. Las obreras textiles, quienes constituían el sector más explotado de la clase trabajadora, fueron quienes removieron los cimientos del régimen zarista al grito de "Pan, paz y abajo la autocracia". La revolución obrera de 1917 puso en debate el amor, la sexualidad, la familia, el trabajo doméstico, el derecho al divorcio y al aborto, entre tantas otras cuestiones de la vida cotidiana. La clase trabajadora se atrevió no sólo a tomar el poder, sino también a tomar el cielo por asalto, pensando nuevas formas de relaciones humanas, despojadas de la represión, el despotismo y la mezquindad familiar contra el telón de fondo del desgarramiento entre una sociedad por nacer y la vieja sociedad opresora que se derrumbaba. Fue necesario asfixiar la revolución y liquidar (mediante fusilamientos, exilio y campos de trabajo forzoso) a toda la generación del Partido Bolchevique que fue su protagonista, para retroceder en los derechos conquistados por las mujeres bajo el régimen de los soviets. 


\section{Revolución, sustantivo femenino}

Palabras clave: amor libre; mujeres trabajadoras; Día de la Mujer; emancipación femenina; trabajo doméstico; Alexandra Kollontai

\section{ABSTRACT}

"It had not occurred to anyone that Women's Day might become the first day of the revolution", says Leon Trotsky in his History of the Russian Revolution. Textile workers, who comprised the most exploited sector of the working class, were the ones who removed the foundations of the Tsarist regime, with the scream: "Bread!" "Peace!" and "Down with the Autocracy!" The proletarian revolution of 1917 brought into discussion love, sexuality, family, domestic work, the right to divorce and abortion, among many other issues of the daily life. The working class dared not only to take power but also to take the sky, thinking new forms of human relations, stripped of family repression, despotism and pettiness, in the middle of a rising society and the old oppressive society that begun to collapse. It was necessary to stifle the Revolution and to destroy (by means of execution, exile, and forced labor camps) the generation of the Bolshevik Party who had played a leading role in it, in order to retreat in the rights conquered by women under the regime of the Soviets.

Keywords: free love; workers women; Woman's Day; emancipation of women; domestic work ; Alexandra Kollontai

\section{Introducción}

Existe un amplio consenso sobre el gigantesco paso adelante que significó, para la vida de las mujeres rusas, el triunfo de la revolución proletaria de 1917. Sus ecos resonaron también en otros continentes y las sufragistas, las mujeres que bregaban por la educación femenina, las feministas liberales y distintos sectores progresistas de los países de Occidente saludaron la avanzada legislación, las políticas públicas y el desarrollo conquistado en las lejanas estepas europeas.

Lo más sugestivo era que las noticias provenían de Rusia, un país sumido en el atraso cultural y económico: las mujeres asaltaban el cielo nada menos que allí, en el viejo reinado de los patriarcas

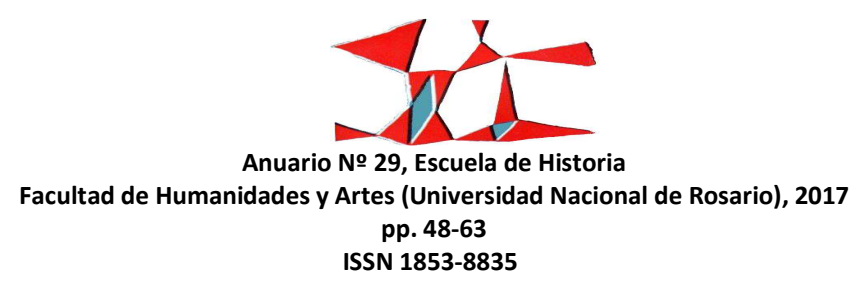


ortodoxos y los zares, de los cosacos embriagados por barriles de vodka, del campesinado sumido en el analfabetismo y de los kulaks ${ }^{1}$ enriqueciéndose a fuerza de latigazos.

Y esto ocurría nada menos que en 1917, cuando Rusia atravesaba la devastación que provocaba la Primera Guerra Mundial, que había reducido su producción industrial a la quinta parte. Para 1917, siete millones y medio de rusos habían muerto sólo por hambre y tifus. Además, la república de los soviets ${ }^{2}$ nacía rodeada por el ejército alemán, la flota inglesa, tropas checoslovacas, francesas, americanas y serbias, el ejército japonés y los jefes cosacos de las antiguas fuerzas imperiales; con una población diezmada no sólo por la guerra imperialista, sino también por la guerra civil, las sequías y las plagas.

En ese terreno -previsiblemente árido para el florecimiento del progreso cultural y político-, se instauró la igualdad legal entre hombres y mujeres; el derecho de la mujer a la propiedad; se abolió el matrimonio eclesiástico; se reconocieron las uniones de hecho; se estableció la igualdad de derechos para los hijos nacidos de matrimonios legales y de uniones de hecho; se estableció el derecho al divorcio y al aborto; la educación mixta; se crearon guarderías, lavanderías y comedores comunitarios; se eliminó la criminalización de la homosexualidad y la persecución a las mujeres en situación de prostitución. Como señala Jean Marabini: "La Revolución de Octubre transforma el paisaje habitual de un país, los pensamientos de un pueblo, modifica la vida del individuo, de la pareja, de la familia, al punto de hacer desaparecer, por lo menos temporalmente, ese individuo, esa pareja, esa familia, ese país, ese pueblo. Un movimiento tan radical como ése subvierte la noción de 'pausa', frente al historiador acostumbrado a investigar, en general, sobre el inventario de una civilización petrificada." ${ }^{3}$

Pero estas innovaciones que revolucionaron la vida cotidiana de las mujeres y de los hogares rusos, no cayeron del cielo, ni tampoco surgieron espontáneamente bajo el estímulo de la revolución social. El partido dirigido por Lenin era un hervidero de debates acerca de la emancipación femenina, la disolución de

\footnotetext{
${ }^{1}$ Del ruso, era el nombre con que se denominaba a los campesinos acomodados, que poseían propiedades y empleaban trabajadores.

2 En ruso, "consejo", es una asamblea de trabajadores. Los primeros soviets, conformados por trabajadores, soldados y campesinos, surgieron durante la revolución rusa de 1905. En 1917, fueron la base para la formación de la República Socialista Federativa Soviética de Rusia, primero, y de la Unión de Repúblicas Socialistas Soviéticas, en 1922. La Constitución soviética de 1918, con los bolcheviques ya en el poder, organizó la administración política del Estado en un sistema inversamente jerárquico y democrático es decir, de abajo arriba- de consejos (sóviets) de obreros, campesinos y soldados.

${ }^{3}$ Jean Marabini; A Rússia durante a Revolução de Outubro; p.7
}

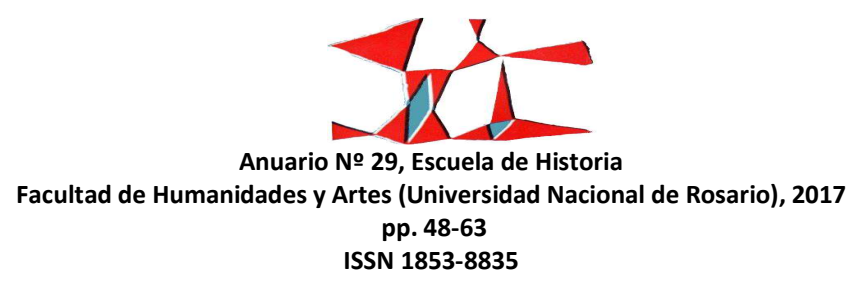




\section{Revolución, sustantivo femenino}

la familia burguesa y la unión libre; encarnaba la herencia libertaria de las rebeliones de esclavos de la Antigüedad, que había resucitado en las sectas igualitaristas y comunistas de los albores del capitalismo; era heredero del socialismo utópico y también de esa crítica implacable que Marx y Engels le habían propinado, con ironía, al matrimonio burgués y a la familia en el Manifiesto Comunista.

Sostenemos aquí que, esa relación entre un ideario heredado del socialismo utópico, incluyendo los análisis críticos del materialismo histórico, y la incorporación masiva de las mujeres en las concentraciones industriales de las grandes ciudades europeas, alentada aún más por la necesidad de fuerza de trabajo que imponía la movilización de los obreros al frente de batalla durante la Primera Guerra Mundial, produjeron una experiencia inédita en el marco de la Revolución Rusa de 1917.

La combinación de ese "nuevo proletariado" constituido por mujeres -uno de los sectores más oprimidos y explotados-, que a su vez soportaba las condiciones de hambre y carestía impuestas por la contienda bélica, con una dirigencia revolucionaria imbuida de las ideas más avanzadas sobre la emancipación femenina son el fundamento de las audaces medidas adoptadas por el Partido Bolchevique, traducidas en legislación, planes de gobierno y políticas sociales.

El contenido se ha organizado en cuatro partes. En la primera, se esbozan las principales ideas relativas a la emancipación de la mujer y el amor libre y de qué manera se tradujo la preocupación por sostener los ideales libertarios sin que esto tuviera una consecuencia negativa para las mujeres, obligadas por las ancestrales costumbres patriarcales- a cargar con las responsabilidades de la prole.

En segundo lugar, se sintetizan las condiciones particulares en las que se encontraban las mujeres trabajadoras rusas en los años previos a 1917 y cuál fue la política que las dos corrientes del Partido Obrero Socialdemócrata Ruso tuvieron hacia este nuevo fenómeno social, incluyendo la conmemoración del Día Internacional de las Mujeres el que, finalmente, en 1917 fue el día del inicio del proceso revolucionario que culminó ocho meses después, con el asalto al Palacio de Invierno y la toma del poder.

En una tercera parte, mencionamos los aspectos más destacados de la política del estado obrero hacia las mujeres: la redacción del nuevo Código Civil de 1918 y las medidas basadas en los cuatro pilares programáticos concernientes a la socialización del trabajo doméstico, la incorporación de las mujeres al trabajo productivo, la extinción de la familia y la legitimidad de las uniones libres.

51

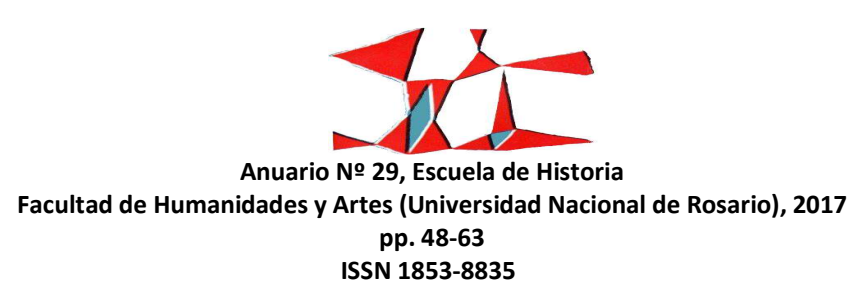


Por último, abordamos una breve explicación de cómo el stalinismo provocó un retroceso descomunal en las medidas más avanzadas de la revolución de 1917, en estas áreas y cuáles fueron las condiciones para que ese repliegue en las conquistas de las masas pudiera imponerse.

\section{El amor libre}

Desde la Edad Media que la humanidad reflexiona sobre la libertad en el amor y se han constituido sectas, movimientos y asociaciones que rechazan los sistemas contractuales, los matrimonios concertados por terceros o la injerencia de la Iglesia y/o el Estado en las relaciones sexoafectivas entre las personas. No solamente el matrimonio es cuestionado por las distintas corrientes que postulan el ideal del amor libre, sino también las reglamentaciones acerca del adulterio y las prohibiciones que atañen a la anticoncepción y el aborto, entre otros tópicos. Por eso, en general, casi todos los movimientos que defienden el amor libre, también cuestionan la sujeción de la mujer al varón, su falta de libertad y, por lo tanto, son partidarios de la emancipación de las mujeres.

Quizás sea más preciso referirse a la "unión libre", antes que al amor libre, cuando nos referimos a la Rusia de la revolución proletaria de 1917. La preocupación central entre los dirigentes e intelectuales del bolchevismo consistía en acabar con la desigualdad existente entre las relaciones sexoafectivas legalizadas por la Iglesia Ortodoxa bajo el régimen zarista y las uniones de hecho, además de sus consecuentes desigualdades para los hijos e hijas concebidas en por unas y otras parejas.

También esto traía consecuencias para la vida de las mujeres, cla libertad en las uniones sexoafectivas traía las mismas consecuencias para aquellas a las que el matrimonio significaba su único modo de supervivencia? ¿No era necesario, acaso, impulsar audazmente la emancipación de las mujeres conquistando su incorporación al trabajo productivo, su independencia económica, su igualdad ante la ley para entonces establecer la legitimidad de las uniones libres?

Kollontai proclamaba la necesidad de construir un amor de camaradas, contra las relaciones posesivas que configuraba el ideal burgués del "amor romántico": "Si logramos que de las relaciones de amor desaparezca el ciego, exigente y absorbente sentimiento pasional; si desaparece también el

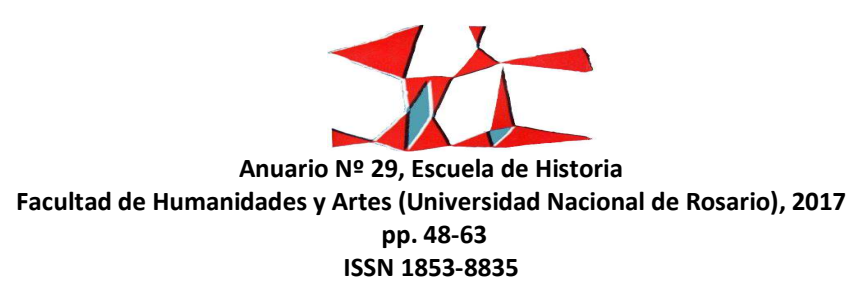




\section{Revolución, sustantivo femenino}

sentimiento de propiedad lo mismo que el deseo egoísta de 'unirse para siempre al ser amado'; si logramos que desaparezca la fatuidad del hombre y que la mujer no renuncie criminalmente a su 'yo', no cabe duda que la desaparición de todos estos sentimientos hará que se desarrollen otros elementos preciosos para el amor. Así se desarrollará y aumentará el respeto hacia la personalidad del otro, lo mismo que se perfeccionará el arte de contar con los derechos de los demás; se educará la sensibilidad recíproca y se desarrollará enormemente la tendencia de manifestar el amor no solamente con besos y abrazos, sino también con una unidad de acción y de voluntad en la creación común." ${ }^{4}$ La dirigente revolucionaria se esforzaba por demostrar que esa forma de pasión, surgida históricamente con el ascenso de la burguesía, encarnaba el concepto de propiedad privada trasladado a las relaciones personales, cosificando a las personas, engendrando los celos y por lo tanto, siendo también la fuente de múltiples formas de violencia.

Ya desde 1911, Kollontai interpelaba furiosamente las relaciones existentes entre los sexos y la necesidad de pasar la vida afectiva, también por el prisma de la revolución: "Es imperdonable nuestra actitud de indiferencia ante una de las tareas esenciales de la clase obrera. Es inexplicable e injustificable que el vital problema sexual se relegue hipócritamente al casillero de las cuestiones 'puramente privadas'. ¿Por qué negamos a este problema el auxilio de la energía y de la atención de la colectividad? Las relaciones entre los sexos y la elaboración de un código sexual que rija estas relaciones aparecen en la historia de la humanidad, de una manera invariable, como uno de los factores esenciales de la lucha social. Nada más cierto que la influencia fundamental y decisiva de las relaciones sexuales de un grupo social determinado en el resultado de la lucha de esta clase con otra de intereses opuestos." ${ }^{5}$

Habiéndose hecho del poder del Estado, la clase obrera tenía la oportunidad de poner en práctica, en un gigantesco laboratorio social, aquello que había promulgado como un credo revolucionario.

\section{La chispa que encendió la llama}

Durante una década, bajo el régimen zarista, las mujeres habían protagonizado enormes luchas en el seno de la naciente clase obrera rusa: a las reivindicaciones económicas, frecuentemente, añadían las demandas de guarderías en las fábricas, pago de licencia por maternidad, tiempo libre para amamantar a

\footnotetext{
${ }^{4}$ Kollontai, Alexandra; Carta a la juventud obrera; Marxist Internet Archive; 1923.

${ }^{5}$ Kollontai, Alexandra; Las relaciones sexuales y la lucha de clases; Marxist Internet Archive; 1911.
}

53

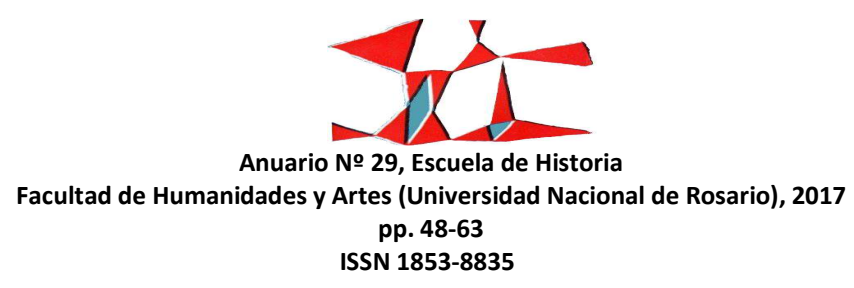


los recién nacidos, etc. En los registros policiales y de las fábricas, abundan los ejemplos de huelgas de mujeres que reclaman poder usar los mismos baños que usan los dueños de la empresa, que cese el abuso de los capataces y que se prohíba insultar a las obreras.

La guerra significó una carga adicional sobre sus hombros. Mientras eran movilizados al frente casi diez millones de hombres -en su mayoría, campesinos-, las mujeres se convirtieron en obreras agrícolas alcanzando a representar el 72\% de los trabajadores rurales. Entre 1914 y 1917, la fuerza de trabajo femenina en las fábricas se incrementó casi en un $50 \%$.

Sobre ese fermento, el Partido Obrero Socialdemócrata de Rusia ${ }^{6}$ desarrolló una política audaz para el reclutamiento de jóvenes obreras, al tiempo que educaba a los trabajadores para que éstos asumieran la lucha por la emancipación de las mujeres.

El 26 y 27 de agosto de 1910, se había realizado en Copenhague la II Conferencia Internacional de Mujeres Socialistas, donde los principales debates habían girado en torno al derecho al sufragio para las mujeres y la legislación para la protección de la maternidad. Las delegadas Clara Zetkin y Kate Duncker, del Partido Socialdemócrata Alemán, propusieron allí la conocida moción de establecer la conmemoración de un Día Internacional de las Mujeres. Contrariamente a la historia que se ha divulgado ampliamente sobre el incendio de la textil Cotton, en Estados Unidos, la propuesta de las socialistas alemanas no incluía la referencia a ningún hecho histórico, por eso tampoco indicaba una fecha precisa para la realización de actos y manifestaciones. Su propuesta decía: "De acuerdo con las organizaciones políticas y sindicales del proletariado, las mujeres socialistas de todas las nacionalidades organizarán en sus respectivos países un día especial de las mujeres, cuyo principal objetivo será promover el derecho al voto de las mujeres. Será necesario debatir esta proposición en relación a la cuestión de la mujer desde la perspectiva socialista. Esta conmemoración deberá tener un carácter internacional y será necesario prepararla con mucho esmero."

En Rusia, el Día Internacional de las Mujeres se conmemorará por primera vez en 1913 y los bolcheviques ${ }^{7}$ lanzarán un suplemento especial de su periódico. Para 1914, al igual que las socialistas

\footnotetext{
${ }^{6}$ El Partido Obrero Socialdemócrata de Rusia (POSDR) fue fundado en 1898 en Minsk, cuando se reunieron en su primer congreso diversas organizaciones marxistas de San Petersburgo, Moscú, Kiev, junto a la Unión General de Trabajadores Judíos de Lituania, Polonia y Rusia. Su fundación fue preparada desde 1883 por el grupo Emancipación del Trabajo, creado por Plejánov, que polemizaba con Voluntad del Pueblo, otra organización revolucionaria de ideología populista.
}

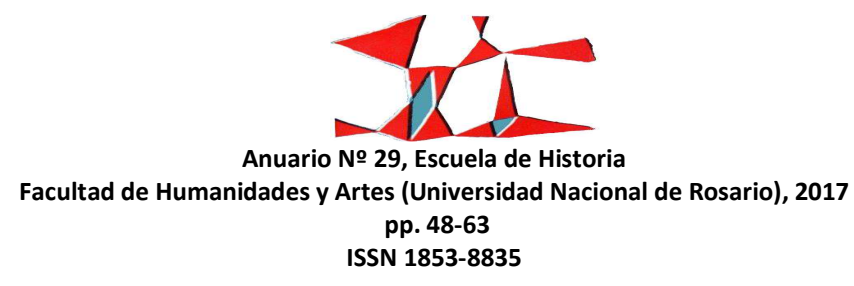




\section{Revolución, sustantivo femenino}

alemanas y suecas, las rusas acordaron que la conmemoración se haría el 8 de marzo, fecha que mantuvieron en los años siguientes.

Mientras la tendencia menchevique ${ }^{8}$ postulaba que sólo las mujeres debían participar en las manifestaciones conmemoratorias, los bolcheviques sostenían que esta fecha debía ser conmemorada por toda la clase obrera, porque la emancipación femenina debía ser asumida como una bandera de lucha por el conjunto de los explotados. Fueron los bolcheviques quienes, por sugerencia de Lenin, publicaron un periódico íntegramente dedicado a las mujeres trabajadoras, llamado Rabotnitsa. ${ }^{9}$

Una de las dirigentes menchevique más comprometida con la organización de las mujeres obreras, era Alexandra Kollontai quien fue atacada por el régimen zarista, precisamente por esta labor. Ante esta persecución política, la dirección de la fracción menchevique -en la editorial de su periódico Voz Socialdemócrata- se deslindó de responsabilidad por la actividad que Kollontai llevaba adelante, aclarando que se oponía a la organización independiente de las trabajadoras. Ésta, entre otras diferencias mantenidas con la orientación política del menchevismo, impulsaron a Kollontai a integrarse, tiempo después, a las filas dirigidas por Lenin.

En tanto, la guerra hacía estragos y en 1915, las mujeres que protagonizaban motines, sabotajes y acciones desesperadas en las principales ciudades de Europa, también en San Petersburgo arremetían contra un mercado de comestibles, saqueando todo aquello que necesitaban para paliar el hambre de sus familias. La escena se repetía en Moscú y volvía a ocurrir al año siguiente. Aquellas consignas que las obreras textiles de San Petersburgo popularizaron en el Día Internacional de las Mujeres de 1917, se gestaron en cada una de estas revueltas provocadas por las penurias: fin de la guerra, retiro de las guardias de cosacos de las fábricas, libertad para los bolcheviques exiliados y todos los presos políticos.

La policía zarista advertía del peligro que se estaba incubando entre los estómagos vacíos y los cementerios repletos de cadáveres: "las madres de familia, agotadas por las colas interminables de los comercios, atormentadas por el aspecto hambriento y enfermo de los niños, están más abiertas ahora a la

\footnotetext{
7 En ruso, "miembro de la mayoría". Se denominaba así a los integrantes de una de las tendencias en las que se encontraba dividido el Partido Obrero Socialdemócrata de Rusia, a partir de 1903. Los bolcheviques estaban dirigidos por Lenin. La tendencia minoritaria eran los mencheviques.

${ }^{8}$ Los mencheviques se escindieron totalmente del Partido Obrero Socialdemócrata de Rusia a partir de 1912.

${ }^{9}$ En ruso, La Obrera.
}

55

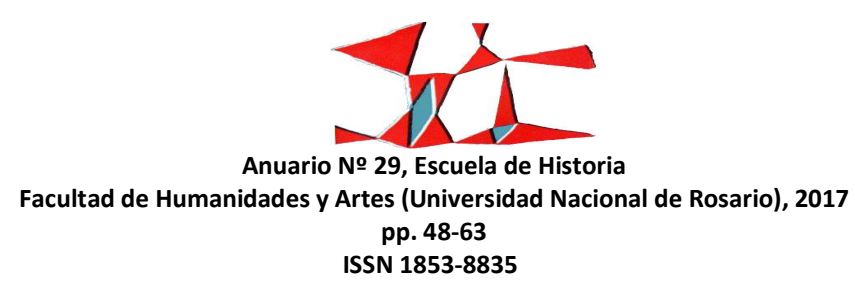


revolución, que el señor Miliukov, Rodichev y compañía, y por supuesto, son más peligrosas porque ellas representan la chispa que puede encender la llama"10, decían en un reporte previo al levantamiento del mes de febrero de 1917.

La advertencia llegaba demasiado tarde: el 23 de ese mes -que corresponde al 8 de marzo del calendario occidental-, las obreras textiles se declararon en huelga para conmemorar el Día Internacional de las Mujeres. El pliego de reclamos era escueto: pan, paz y abajo la autocracia. “El 23 de febrero era el Día Internacional de la Mujer. Los socialdemócratas se proponían festejarlo en la forma tradicional: con asambleas, discursos, manifiestos, etc. A nadie se le pasó por las mentes que el Día de la Mujer pudiera convertirse en el primer día de la revolución." ${ }^{11}$ Así empieza uno de los capítulos de la Historia de la Revolución Rusa, escrita por León Trotsky.

\section{La emancipación de las mujeres, pilar de la revolución}

Si tamañas transformaciones fueron posibles apenas con la toma del poder, fue porque se apoyaban en ese fermento femenino que fue capaz de encender la chispa de la revolución. Y porque la imaginación de los bolcheviques resultó ser más transgresora y potente que las adversidades que se cernían sobre el naciente estado obrero.

Pero, como sostenía Lenin, la igualdad ante la ley era apenas el inicio, el mínimo paso que podía dar la revolución a favor de las mujeres, pero no era aún la igualdad ante la vida. Y la revolución tenía que, al menos, intentar avanzar en este sentido. "Una revolución no es digna de llamarse tal si con todo el poder y todos los medios de que dispone no es capaz de ayudar a la mujer -doble o triplemente esclavizada, como lo fue en el pasado- a salir a flote y avanzar por el camino del progreso social e individual", escribirá León Trotsky, años más tarde. ${ }^{12}$

Las transformaciones legales debían estar acompañadas de la monumental tarea de eliminar la "esclavitud doméstica", aquella doble jornada sin remuneración que sobrecargaba las espaldas de las mujeres. Mientras las feministas más avanzadas de la época se proponían el objetivo de que las tareas

\footnotetext{
${ }^{10}$ Citado por Bárbara Funes; en cap. "Rojas"; de D’Atri, Andrea (compiladora) Luchadoras. Historias de mujeres que hicieron historia; Ediciones del IPS; Buenos Aires; 2006.

${ }^{11}$ Trotsky, León; Historia de la Revolución Rusa; cap. VII; Marxist Internet Archive

12 Trotsky, León; Problemas de la vida cotidiana; Grupo Germinal; 1923; p.18.
}

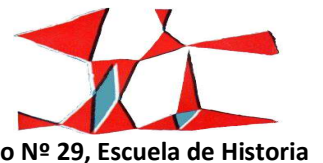




\section{Revolución, sustantivo femenino}

domésticas fueran compartidas por los varones de la familia, los bolcheviques fueron más ambiciosos y proclamaron la necesidad de eliminar ese trabajo tedioso, invisible y no remunerado. Convertir los quehaceres del hogar en un trabajo asalariado, industrializado y por lo tanto, pasible de ser efectuado por hombres y mujeres, colectivamente, remunerados por el estado obrero, era un paso crucial para avanzar en la emancipación femenina.

Desde el ministerio de Asistencia Pública, Alexandra Kollontai, pronto se convirtió en una de las artífices de gran parte de las reformas que se introdujeron en la legislación sobre la mujer y la familia. Entre las medidas más destacadas que tomó la nueva ministra del estado obrero se encuentran el permiso para que las mujeres soviéticas pudieran elegir libremente su profesión, la equiparación salarial con los varones por el mismo trabajo, el acceso asegurado de las mujeres a todos los empleos del Estado, la prohibición de los despidos de mujeres embarazadas, el derecho de las mujeres casadas a no seguir a su marido y la educación mixta.

En 1918, Inessa Armand, dirigente bolchevique, intervino, entusiastamente, en el Congreso de Mujeres Obreras y Campesinas, con estas palabras: "Bajo el capitalismo, la mujer obrera debe soportar el doble fardo de trabajar en la fábrica y luego realizar las tareas domésticas en el hogar. No solamente debe hornear y tejer para el patrón, sino que también debe lavar, limpiar y cocinar para su familia. Pero hoy es diferente. El sistema burgués está en vías de desaparición. Nos acercamos a la época de construcción del socialismo. Para reemplazar los millones y millones de pequeñas unidades económicas individuales (...) debemos crear estructuras colectivas ejemplares, de cocinas, comedores y lavanderías." ${ }^{13}$

La emancipación de las mujeres no era una tarea secundaria de la revolución proletaria, sino uno de los pilares fundamentales. Por eso fue crucial tener en cuenta este ángulo, para diseñar el nuevo Código Civil, que fue precedido de largos, profundos e interesantes debates. El historiador Henri Chambre señala que la legislación soviética se sometía a dos principios fundamentales, que partían de este punto de vista: "la emancipación de la mujer y la desaparición de la desigualdad de derechos entre el hijo natural y el hijo legítimo." ${ }^{14}$

${ }^{13}$ Citada por Landa, Verónica en "Rescatando la experiencia de la bolchevique Inessa Armand"; La Izquierda Diario, 22/2/2017.

${ }^{14}$ Citado por Liebman, Marcel en La conquista del poder; Grijalbo; México DF; 1978.

57

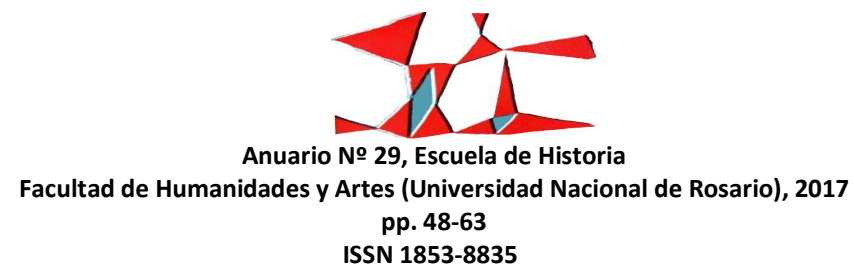


Su objetivo era proteger a las mujeres de las consecuencias que, por su situación ancestral de desigualdad con respecto a los varones, podían provocar las nuevas normas que introducían mayores libertades respecto de las formas tradicionales de familia. El Código Civil fue considerado ultraizquierdista por algunos y relativamente conservador, por otros, como Alejandra Kollontai quien sostenía que el Estado no debe tener ningún tipo de injerencia en las relaciones sexoafectivas de los adultos que profesan su consentimiento mutuo.

Al igual que Henri Chambre, la historiadora norteamericana Wendy Z. Goldman indica que, "desde una perspectiva comparativa, el Código de 1918 se adelantaba notablemente a su época. No se ha promulgado ninguna legislación similar con respecto a la igualdad de género, el divorcio, la legitimidad y la propiedad ni en América ni en Europa. Sin embargo, a pesar de las innovaciones radicales del Código, los juristas señalaron rápidamente 'que esta legislación no es socialista, sino legislación para la era transicional'. Ya que este Código preservaba el registro matrimonial, la pensión alimenticia, el subsidio de menores y otras disposiciones relacionadas con la necesidad persistente aunque transitoria de la unidad familiar. Como marxistas, los juristas estaban en la posición extraña de crear leyes que creían que pronto se convertirían en irrelevantes." 15

Esta nueva forma de pensar el Código Civil se fundaba en que, para los bolcheviques, la revolución era apenas un acto, el inicio de un proceso de cambios profundos en los valores y la cultura que se habían reproducido durante milenios. León Trotsky señalaba, en su reconocida teoría de la revolución permanente, que uno de los aspectos esenciales que caracteriza a una revolución socialista es, justamente, esa metamorfosis que, mediante una lucha interna constante, engloba al conjunto de las relaciones sociales. La emancipación de las mujeres del yugo que, por siglos, las mantuvo subordinadas y oprimidas, era uno de los aspectos fundamentales de esas relaciones sociales destinadas a ser transformadas radicalmente.

Por eso, lejos de todo reduccionismo economicista o sectarismo anti-femenino, para los marxistas, la emancipación de las mujeres no era una cuestión secundaria sino una tarea central de la revolución proletaria. En este sentido, establecieron cuatro pilares programáticos que consideraban fundamentales para poder avanzar en un camino emancipatorio: 1) la incorporación de las mujeres al trabajo asalariado, 2) la socialización del trabajo doméstico, 3) la extinción de la familia y 4) el amor o la unión libre.

${ }^{15}$ Goldman, Wendy Z.; La Mujer, el Estado y la Revolución; Ediciones IPS; Buenos Aires; 2010.

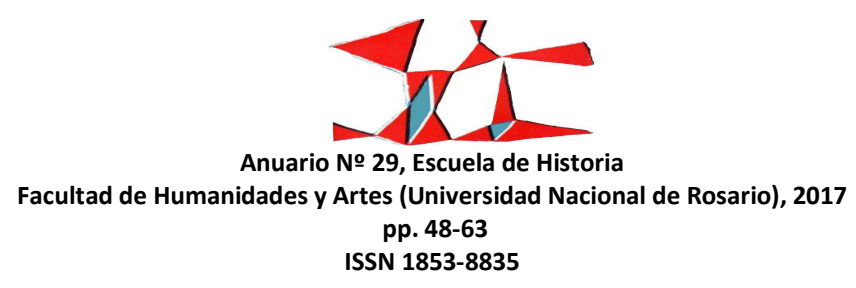




\section{Revolución, sustantivo femenino}

Es decir que, tal como lo sostenía Lenin, las reformas legales no podían ser suficientes para alcanzar la igualdad ante la vida. Por eso, quizás el logro más importante de la revolución fue haber sentado las bases para un pleno y verdadero acceso de la mujer a los dominios culturales y económicos. "De poco hubiera servido el derecho al voto si las mujeres -esclavas domésticas, según la definición de Leninhubieran seguido siendo las únicas que cargaran con las obligaciones del hogar familiar, las más limitadas en su acceso a la educación, las que no tenían ningún acceso a la producción." ${ }^{16}$

Las tareas domésticas llevadas a cabo por las mujeres, de manera aislada en sus hogares individuales, debían ser sustituidas por un sistema de servicios sociales garantizados por el Estado: guarderías, jardines de infantes, lavanderías y comedores colectivos, además de hospitales, cines, teatros, que permitieran el acceso de las masas a la salud y la cultura. Para los revolucionarios de la época, las funciones económicas de la familia debían ser absorbidas por la sociedad socialista, emancipando a las mujeres del yugo de las tareas domésticas. Más aun cuando se alentaba la incorporación de las masas femeninas al trabajo productivo y a ocupar crecientemente, mayores funciones en el aparato del Estado.

De este modo, la independencia económica de las mujeres y la liberación de la carga del trabajo doméstico, permitirían no sólo una mayor participación de las masas femeninas en la vida social, cultural y política sino que, además, sentaban las bases para nuevas formas de relaciones sexoafectivas, liberadas de la coerción económica en la que se fundaban las viejas costumbres patriarcales. Para la dirigencia bolchevique, la extinción de la familia patriarcal era el proceso que, lógicamente, iba a darse sobre estas nuevas bases que abrían paso a las uniones libres, basadas exclusivamente en el interés sexual y afectivo mutuos.

Adelantándose a su época, Trotsky señalaba en los albores de la revolución que "la primera tarea, la más profunda y urgente, es la de romper el silencio que rodea a los problemas de la vida cotidiana."17 Romper ese silencio significaba dar el primer paso en las más radicales transformaciones de la vida, fundamentalmente, de las mujeres.

\footnotetext{
${ }^{16}$ D’Atri, Andrea; Un análisis del rol destacado de las mujeres socialistas en la lucha contra la opresión y de las mujeres obreras en el inicio de la Revolución Rusa [Conferencia en el Centro Cultural Rosa Luxemburgo, Ciudad de Buenos Aires, octubre 2003].

17 Trotsky, León; Problemas de la vida cotidiana; op.cit.
}

59

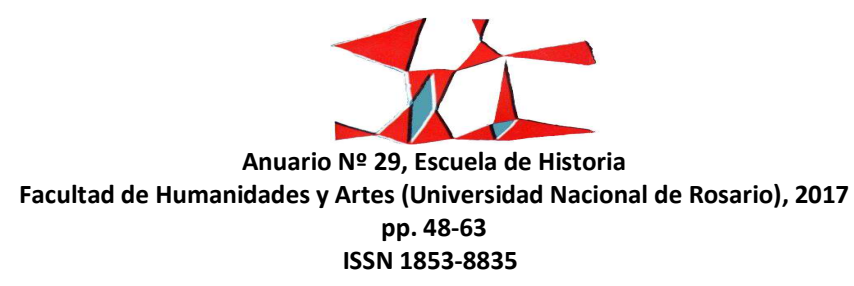




\section{La reacción stalinista}

Y, sin embargo, ¿cómo fue posible que ese estado obrero -surgido de la revolución proletaria, y destinado a extinguirse- se transformara, en menos de una década, bajo el régimen de la burocracia estalinista, en el gendarme de la vida cotidiana?

La incorporación de las mujeres al trabajo asalariado, imaginado como una medida libertaria para millones que alcanzaron una autonomía desconocida hasta entonces, se transformó en su contrario. El trabajo asalariado se convirtió en una pesada carga cuando se redujeron los servicios comunitarios y, al igual que en los países capitalistas, las mujeres volvieron a asumir la doble jornada que las hacía responsables por las tareas domésticas.

Pero, además, el Estado también se encargó de inculcar la idea de que las mujeres se realizaban verdaderamente como tales, en la maternidad, como esposas y amas de sus hogares. El estado obrero, ahora burocratizado, se convirtió en una fenomenal máquina de propaganda del orden familiar basado en la autoridad del marido, la subordinación de las mujeres y la dependencia de los niños.

La familia tradicional que, en Alemania e Italia, era considerada como la base fundamental del disciplinamiento social por parte de los regímenes fascistas, también cumplió ese papel en la Unión Soviética, bajo la égida de Stalin. Todas las ideas libertarias enarboladas en los primeros años de la revolución, del amor y la unión libre, fueron acusadas por los comisarios políticos de propaganda inmoral, pequeñoburguesa y anarquista.

Sin embargo, tal como señala Trotsky en su obra La Revolución Traicionada, de 1936, no fue posible tomar por asalto la antigua familia. La sociedad fue demasiado pobre y demasiado poco civilizada. La emancipación verdadera de la mujer fue imposible en el terreno de la miseria socializada. Además de la imperiosa necesidad económica, que limitó el desarrollo de la socialización de los servicios tales como guarderías, lavaderos, comedores, etc, lo cierto es que la afirmación de la burocracia stalinista en el poder del Estado desenterró el viejo culto a la familia ya que tenía la necesidad "de una jerarquía estable de las

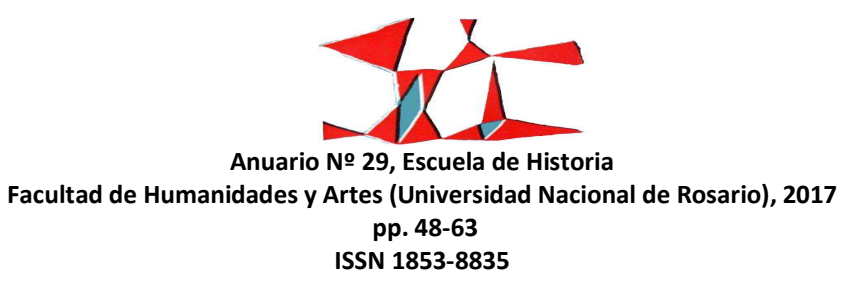




\section{Revolución, sustantivo femenino}

relaciones sociales, y de una juventud disciplinada por cuarenta millones de hogares que sirven de apoyo a la autoridad y el poder." ${ }^{\prime 18}$

Esta transformación que, inversamente a la realizada por la revolución en 1917, significaba un gigantesco paso hacia atrás, no pudo imponerse sin resistencia. Por eso, a la revolución fue necesario ahogarla con una contrarrevolución: la generación que había participado del levantamiento de 1917 fue aniquilada; quienes no perecieron en la guerra imperialista o en la guerra civil, murieron por el hambre y las enfermedades o fueron deportados, encarcelados en campos de trabajo forzoso o fusilados. Stalin consiguió hacerse del poder del partido y del estado con el apoyo de las nuevas generaciones de arribistas que ingresaron al Partido Bolchevique después de conquistado el poder y de las clases más atrasadas de la sociedad, de las cuales tomó sus prejuicios patriarcales ancestrales, reproduciendo la moral pequeñoburguesa de las masas campesinas. Y también fue necesario derrotar los levantamientos obreros de la moderna Europa, como la revolución alemana, para terminar aislando a la Unión Soviética dentro de sus propias fronteras.

Paradójicamente, en nombre del socialismo real, no sólo se limitó la socialización de los servicios que reemplazaban el trabajo doméstico, ni se desenterró el culto a la familia patriarcal tradicional, sino que también se estableció que el matrimonio civil fuera la única forma legal de unión frente al Estado, se suprimió la sección femenina del Comité Central del Partido Bolchevique -antiguamente presidida por la ya mencionada Inessa Armand-, se criminalizó la prostitución, se persiguió y encarceló a los homosexuales, se prohibió el aborto y se desacreditaron todas las ideas vanguardistas que se habían debatido ardientemente en los primeros años de la revolución.

Como señala Wendy Z. Goldman en su investigación sobre la política hacia las mujeres en la Unión Soviética, lo más trágico de los crímenes cometidos por el estalinismo es que haya llevado adelante esta contrarrevolución, convenciendo de que eso era el socialismo real. Sin embargo, ni siquiera el medio siglo de su existencia al frente del estado obrero - un tiempo efímero, visto con los ojos de la Historia-, pudieron borrar de la memoria colectiva de los oprimidos, el heroico papel que jugaron las mujeres en la Revolución Rusa de 1917 ni tampoco la gran conquista que la revolución socialista significó para ellas, las proletarias del proletario.

${ }^{18}$ Trotsky, León; La Revolución Traicionada; Fundación Federico Engels; Madrid; 2001.

61

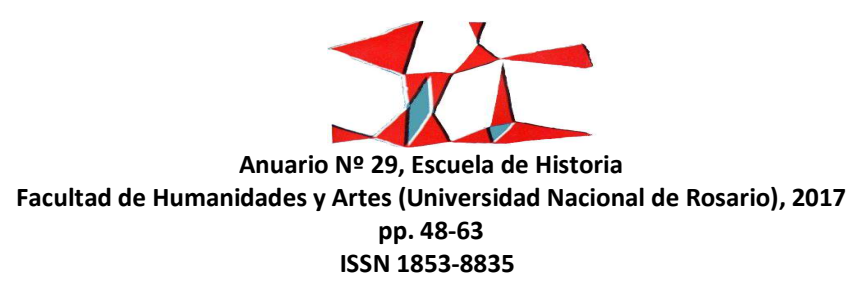


Así como lo hicieron en Francia en 1789, como lo volvieron a hacer en la Comuna de París en 1871, las mujeres rusas de 1917 dieron sobradas muestras de abnegación, coraje y heroísmo. Y la historia continúa dando muestras de este protagonismo de las mujeres trabajadoras y del pueblo pobre a las que seguiremos encontrando encabezando los procesos revolucionarios y las grandes transformaciones sociales. Como señalaba León Trotsky -y que bien podría convertirse en un teorema infalible para los historiadoresserá porque "quienes luchan con más energía y persistencia por lo nuevo son quienes más han sufrido con lo viejo"19.

\section{Bibliografía}

D’Atri, Andrea (compiladora); Luchadoras. Historias de mujeres que hicieron historia; Ediciones del IPS; Buenos Aires; 2006.

Goldman, Wendy Z.; La Mujer, el Estado y la Revolución; Ediciones IPS; Buenos Aires; 2010.

Kollontai, Alexandra; La mujer nueva y la moral sexual; Juan Pablós Editor; México DF; 1986.

Landa, Verónica; "Rescatando la experiencia de la bolchevique Inessa Armand”; La Izquierda Diario, Buenos Aires; 22/2/2017.

Lenin, Vladimir; "Para la historia de una paz infortunada"; en Lenin, V.; Obras Completas, T. XXVI; Editorial Cartago; Buenos Aires; 1958.

Lewin, Moshe; El último combate de Lenin; Lumen; Barcelona; 1970.

Liebman, Marcel; La conquista del poder; Grijalbo; México DF; 1978.

Marabini, Jean; A Rússia durante a Revolução de Outubro; Companhia Das Letras; São Paulo; 1989.

Serge, Victor; El año I de la Revolución Rusa; Ediciones RyR; Buenos Aires; 2011.

Trotsky, León; “Twenty Years of Stalinist Degeneration”; en Fourth International; V. 6, № 3; New York; 1945.

${ }^{19}$ Trotsky, León; Problemas de la vida cotidiana, op.cit.

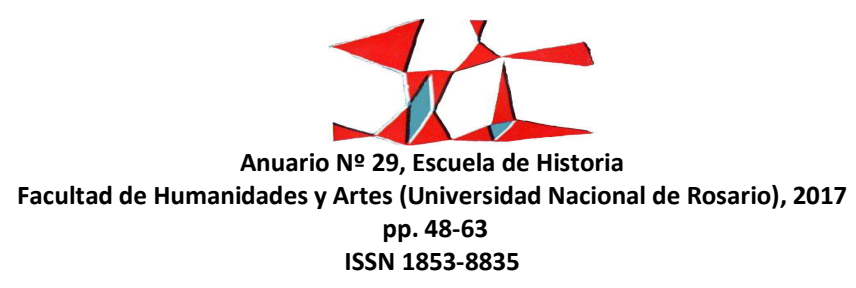




\section{Revolución, sustantivo femenino}

Trotsky, León; Historia de la Revolución Rusa; Sarpe; Madrid; 1985.

Trotsky, León; La revolución traicionada; Claridad; Buenos Aires; 1938.

Trotsky, León; Mi vida; Antídoto; Buenos Aires; 1996.

Trotsky, León; Problemas de la vida cotidiana; Antídoto; Buenos Aires; 2007.

Recibido: 9 de mayo de 2017

Aceptado: 28 de julio 2017

Versión Final: 21 de septiembre de 2017

63

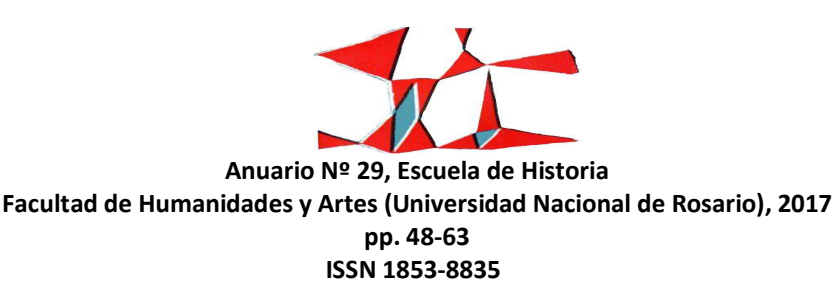

